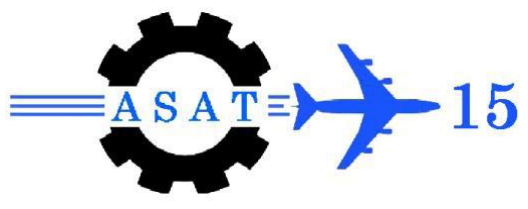

\title{
Dynamic Response of Stiffened Plates Subjected to Underwater Shock Loading
}

\author{
F. Elsayed*, N. M. Nagy ${ }^{\dagger}$
}

\begin{abstract}
The dynamic response of a floating structure subjected to underwater explosion is greatly complicated by the explosion of a high explosive, propagation of shock wave, complex fluid-structure interaction phenomena, and the dynamic behavior of the floating structures. A numerical investigation has been carried out to examine the behavior of stiffened steel plates subjected to shock loads resulting from an Underwater Explosion (UNDEX). The aim of this study is to enhance the dynamic response of stiffened plates to resist underwater shock loading. A non-linear dynamic numerical analysis of the underwater explosion phenomena associated with different geometrical stiffened steel plates is performed using the ABAQUS/Explicit finite element program which provides an important analysis tool that can help engineers and designers to design and construct better structures to resist shock loads. Special emphasis is focused on the evolution of mid-point displacements and the maximum displacements. Further investigations have been performed to study the effects of including material damping and the rate-dependent material properties. The results obtained show that the inclusion of a damping material can absorb energy under blast load. It helps to reduce the force transmitted to the main structure. The inclusion of damping material helps to reduce the displacement of the plates. The results indicate that stiffener configurations affect greatly the overall performance of tested steel plates. The displacement-time histories are presented which will be used in designing stiffened panels so as to enhance resistance to under water shock damage. The obtained numerical results can help in proposing design guidelines for floating structures in order to enhance the resistance to underwater shock damage, since explosive tests are considered costly and dangerous.
\end{abstract}

Keywords: Underwater explosion, stiffened steel plates, shock damage, damping material

\footnotetext{
College of Aerospace and Civil Engineering, Harbin Engineering University, Harbin 150001, China.

† Egyptian Armed Forces, Egypt; nabilmnagy@yahoo.com 


\section{Introduction}

Blast loads caused by explosion generated by accidents or deliberately by terrorist attacks within or immediately nearby ship hull can cause catastrophic damage on the ship structure and shutting down of critical life safety systems. Loss of life and injuries to crew and passengers can result from many causes, including direct blast-effects, structural collapse, debris impact, fire and smoke [1]. The design and analysis of structures subjected to blast loads require a detailed understanding of explosion phenomena and the dynamic response of various structural elements. The most important way to reduce the injuries due to blast loading is to provide sufficient stand-off distance between the structure and explosion source and decrease the effect of the blast wave so that the structure not highly got damaged. To accomplish these objectives, it is necessary to do various scenarios to evaluate the behavior of the ship structure to blast loading. These scenarios should include studying such aspects (explosive magnitude, distance from source of explosion, structure scantling, complex fluidstructure interaction phenomena, structure geometry,......etc.).

Kwon and Cunningham [2] coupled an explicit finite element analysis code, DYNA3D, and a boundary element code based on "Doubly Asymptotic Approximation"(DAA), Underwater Shock Analysis (USA) to obtain the dynamic responses of stiffened cylinder and beam elements. Also, during the early 90s Kwon and Fox [3] studied the non-linear dynamic response of a cylinder subjected to side-on underwater explosion using both the experimental and numerical techniques. Sun and McCoy [4] combined the finite element package ABAQUS and a fluid-structure interaction code based on the DAA to solve an UNDEX analysis of a composite cylinder. Similarly, other researchers [5, 6] coupled a finite element code with a boundary element code such as DAA to capture the fluid-structure interaction effect. Moreover, Adamczyk and Cichocki [7, 8] have performed extensive research to obtain an UNDEX response of simple structures and have implemented entire fluid-structure interaction phenomenon, pressure wave distribution, and the radiation boundary conditions into the commercial finite element package ABAQUS, Fatih Aruka and Ata Mugan [9] performed a numerical simulations to predict the response of a floating structure to an underwater explosion. The analysis was carried out using ABAQUS/Explicit and the results have been visualized using ABAQUS/CAE. The shock loading history, the acceleration, velocity and displacement time histories were presented.

A numerical modeling conducted in a linear dynamic analysis of the plate models with ABAQUS program was carried out by Jacinto et al [10]. Suggestions were made about computational modeling of structures under explosive loading. Schubak et al [11, 12, and 13] studied the response of a one-way stiffened plate under intense loads. The stiffened plate was treated as a single symmetric beam which acts as a large flange. The two stiffened plates are then is modeled as a grillage of beams with asymmetric section. Rigid-plastic and finite element methods were combined for the modeling of orthogonally stiffened plates. Abdelkrim Kadid [14] studied the behavior of stiffened plates subjected to uniform blast loading and indicated that stiffener configurations and time duration can affect the overall behavior of the tested stiffened plates.

A. Forghani, [15] a robust framework for computational modeling of the response of composite laminates to blast loads. The numerical test-bed for the simulations is the explicit finite element code, LS-DYNA. Delimitations were modeled using a cohesive type tiebreak interface introduced between sub-laminates, while intra-laminar damage mechanisms were captured using a continuum damage mechanics approach. Chirica and D.Boazu [16] studied the response of ship hull laminated plates to blast loads using finite-element computer code COSMOS/M. various scenarios to evaluate the behavior of the ship structure laminated plate to blast loading are studied like explosive magnitude, distance from source of explosion, plate thickness. 


\section{Shock Loading from Underwater Explosions}

Non-contact underwater explosion is the major source of threat to ships and submarines. Noncontact underwater explosion effect on the responses and damages of submerged structures is divided into two categories: near-field explosion and far-field explosion depending on the distance between the explosive charge and the target (stand-off distance) [17].

The sudden release of energy from underwater explosions of a conventional high-explosive or nuclear weapon generates a shockwave and forms a superheated, highly compressed gas bubble in the surrounding water $[18,19]$. Of the total energy released from a 1500-lb TNT underwater explosion, approximately $53 \%$ goes into the shockwave and $47 \%$ goes into bubble pulsation. Most cases demonstrate that the damage done to marine structures, such as the surface of ships and submarines, occurs early and is due to the primary shock waves. This investigation only considers the effects of the shock waves.

Figure (1) shows the different events occurring during the UNDEX in a pressure against time history plot as stated in [19]. The under pressure condition as seen in Figure (1) is caused by the back flow of the water toward the explosive due to the contraction of the bubble. The reflection of the shock wave off the bottom of the ocean is a compression wave that adds additional load to the structure. The reflection of the shock wave from free ocean surface causes a reduction in the pressure produced by the shock wave $[17,20]$.

The incident wave is the shock wave produced by the UNDEX charge. The scattered wave is the acoustic field generated by the interaction of the incident wave and the submerged structure. The initial shock wave is modeled as a spherical incident shock wave applied as a transient load active on both the acoustic and structural meshes at their common surfaces (the wetted interface). The distribution of this shock wave onto the plate is obtained by using the incident pressure wave equations [17, 22].
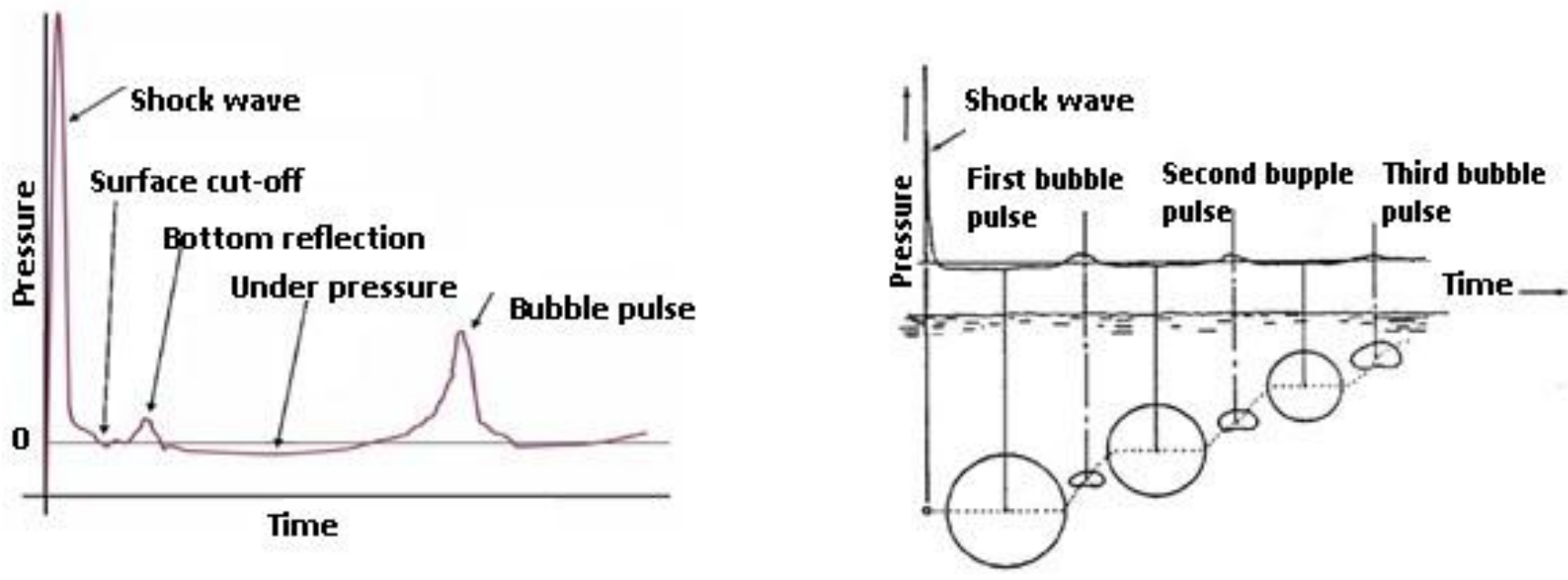

Fig. 1. Phenomenon of the UNDEX: shock wave and high pressure bubble appearing after explosion .[17,20,21]

An underwater shock wave generated by an explosion is superimposed onto hydrostatic pressure. The pressure history, $P(t)$ of the shock wave at a fixed location starts with an instantaneous pressure peak, $P_{\max }$ followed by a decline which is usually approximated by an exponential function. The empirically determined equation of the pressure profile has the following form [15, 23, 24, and 17]:

$P(t)=P_{\max } e^{-\left(\frac{t-t_{1}}{\theta}\right)} t \geq t_{1}$ 
where $t$ is the time elapsed after the detonation of charge in ms, $t_{l}$ is the arrival time of shock wave to the target after the detonation of charge in $\mathrm{ms}, P_{\max }$ is the peak pressure magnitude $(\mathrm{MPa})$ in the shock wave front and $\theta$ is the decay constant which describes the exponential decay in (msec). The peak pressure and decay constant depend upon the size of the explosion and the stand-off distance from this charge at which pressure is measured. The peak pressure, $P_{\max }$, and decay constant, $\theta$, in Eq. (1) are expressed as follows

$P_{\max }=K_{1}\left(\frac{W^{\frac{1}{3}}}{R}\right)^{A_{1}}(M P a)$

$\theta=K_{2} W^{1 / 3}\left(\frac{W^{\frac{1}{3}}}{R}\right)^{A_{2}}(\mathrm{msec})$

where $K_{1}, K_{2}, A_{1}$, and $A_{2}$ are constants that depend on explosive charge type when different explosives are used. These input constants are as stated in Table1 [18, 20, 25, and 17]. $W$ is the weight of the explosive charge in kilograms and $R$ is the distance between the explosive charge and target in meters. Cole [18] also provided further information regarding the systematic presentation of physical effects associated with underwater explosions. When pressure from an underwater explosion impinges upon a flexible surface, such as the hull of surface ship, the reflected pressure on the fluid-structure interaction surface can be predicted reasonable accurately using Taylor's plate theory $[19,20]$. For an airbacked plate of mass per unit area $(m)$ subjected to an incident plane shockwave, $P_{i}(t)$, a reflection wave of pressure, $P_{r}(t)$, leaves the plate, which is moving at velocity $v_{p}(t)$. It can be expressed by using Newton's second law of motion.

$m \cdot \frac{d v_{p}}{d t}=P_{i}+P_{r}(4)$

The fluid particle velocities behind the incident and reflected shockwave are $v_{i}(t)$ and $v_{r}(t)$, respectively; thus, the velocity of the plate becomes

$v_{p}(t)=v_{i}(t)-v_{r}(t)$

The incidence and reflective shock wave pressures are $P_{i}=\rho_{f} c v_{i}$ and $P_{r}(t)=\rho_{f} c v_{r}$ respectively, where $\rho_{f}$ is fluid density and $\mathrm{C}$ is the sound velocity. By substituting the pressure into Eq. (4) and solving with Eq. (1), $P_{r}(t)$ becomes as follows:

$P_{r}(t)=P_{i}(t)-\rho_{f} c v_{p}=P_{\max } e^{-\left(\frac{t-t_{1}}{\theta}\right)}-\rho_{f} c v_{p}$

Eq. (4) can then be rewritten in the form:

$\operatorname{asm} \cdot \frac{d v_{p}}{d t}+\rho_{f} c v_{p}=2 P_{\max } e^{-\left(\frac{t-t_{1}}{\theta}\right)}(7)$

Differentiating Eq. (7) yields the following expression for plate velocity, where $\psi=\frac{\rho_{f c \theta}}{m}$ and $t>0$. The total pressure on the plate is

$P_{t}(t)=2 P_{i}(t)-\rho_{f} c v_{p}=\frac{2 P_{\max }}{1-\psi}\left[e^{-\left(\frac{t-t_{1}}{\theta}\right)}-\psi e^{-\psi\left(t-t_{1}\right) / \theta}\right]$ 


\section{Description of the Plates}

In this investigation, six different steel plates are considered. All the plates are $20 \mathrm{~mm}$ in thickness and $3000 \times 3000 \mathrm{~mm}^{2}$ with rectangular stiffeners of $30 \mathrm{~mm}$ in thickness and $100 \mathrm{~mm}$ in height. Figure (2) shows the different stiffener configurations used in the numerical study.

Table 1: Shock wave parameters for various explosive charge $[18,20,25,17]$

\begin{tabular}{c|c|c|c|c}
\hline \hline \multirow{2}{*}{ Constants } & \multicolumn{4}{|c}{ Explosive material Type } \\
\cline { 2 - 5 } & HBX-1 & TNT & PETN & Nuclear \\
\hline \hline$K_{1}$ & 53.51 & 52.12 & 56.21 & $1.06 \mathrm{E} 4$ \\
\hline$A_{1}$ & 1.144 & 1.180 & 1.194 & 1.13 \\
\hline$K_{2}$ & 0.092 & 0.0895 & 0.086 & 3.627 \\
\hline$A_{2}$ & -0.247 & -0.185 & -0.257 & -0.22 \\
\hline \hline
\end{tabular}

\section{Finite Element Modeling}

In this paper, the non-linear finite element program ABAQUS/Explicit is used to carry out a three-dimensional (3D) analysis of the problem and the results have been visualized in ABAQUS/CAE.

\subsection{Model geometry}

ABAQUS/Explicit program offers an element library for a wide range of geometric models. In the present study, the fourth noded shell element (S4R) with reduced integration and hourglass control was used to model the geometry of the tested plates and stiffeners. Six different models consisting of grids of shell elements of size $0.075 \mathrm{~m}$ were used as shown in Figure (2). The fluid region of the model is represented by an assemblage of 4-node acoustic tetrahedral elements (AC3D4) as shown in Figure (3). The outer boundary of the external fluid is represented by half cylindrical surface as shown in Figure (4).

\subsection{Boundary conditions and fluid-structure coupling}

The panel on the ship's frame is typically stiffened by beams or stringers; thus, the panel can be divided into many small panels. The restraining moment of the borders of these panels is the torsional rigidity of a girder of stringer. During analysis, fully clamped boundary conditions are imposed on the four sides of the panels. The boundaries of the fluid may cause shock wave refraction or reflection, resulting in its superposition or cancellation by the incident wave. To prevent this phenomenon, the boundary condition of the fluid element is set as a non-reflective boundary during analysis except the free surface where zero pressure boundary condition was applied to it as shown in Figure (4) [20].

The acoustic-structural interaction between the wet surfaces of the plat and the acoustic interaction surfaces (the wetted interface) was implemented by use of a surface-based "tie" constraint, the location of the charge and the stand-off point defined as reference points, prior to the interaction, the "INCIDENT WAVE PROPERTY" option is used to specify the incident wave as spherical. The data lines for this option are used to define the location of the standoff point and source point in terms of global Cartesian coordinates. The "INCIDENT WAVE" option is used to activate incident wave loading, the load is applied on both the structure and the fluid at their common interface which is similar to a distributed load, more detail in reference [22].

\subsection{Material properties}

The used stiffened panel is made of mild steel. The numerical model uses the constitutive law for elastic/plastic materials to model the stiffened panel. Isotropic hardening rules are adopted 
in the hardening model. The properties of the mild steel used in the numerical model are as follows:

The poisson ratio is equal to 0.3 and the Mass density is equal to $7800.0 \mathrm{~kg} / \mathrm{m}^{3}$. The initial yield stress is $300 \mathrm{MPa}$, and the yield stress increases to $400 \mathrm{MPa}$ at a plastic strain of $35 \%$. Table 2 shows the plastic material properties for the mild steel used in this study.

Some materials, such as mild steel, show an increase in the yield stress with increasing strain rate. In this research the loading rate is too high, so strain-rate dependence is likely to be very effective. When the material sustains momentary dynamic loading, the effect of the strain rate cause the material's dynamic strength to exceed the static strength during a static experiment; thus, the effect of strain rate should be considered during the analysis to match actual situations. As recommended by Jones [21] this study adopts the Cowper-Symonds strain rate mode as follows:

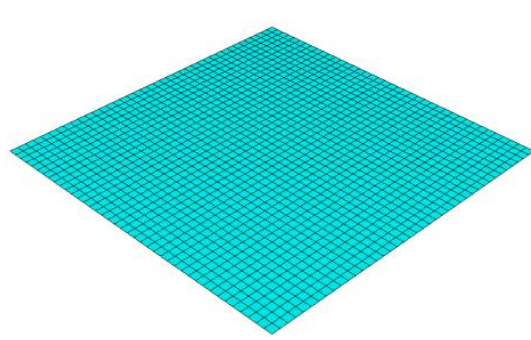

Model 1

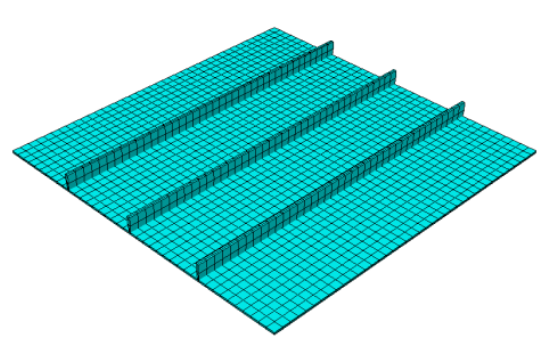

Model 4

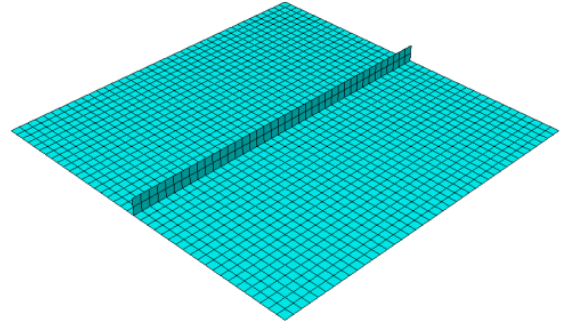

Model 2

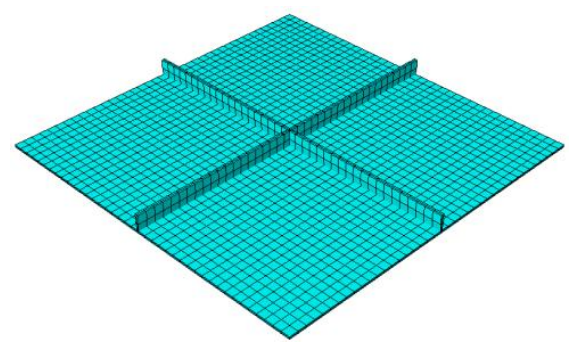

Model 5

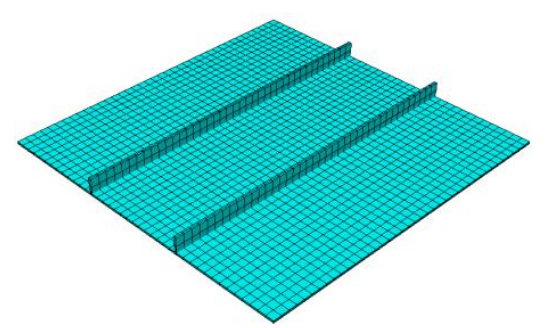

Model 3

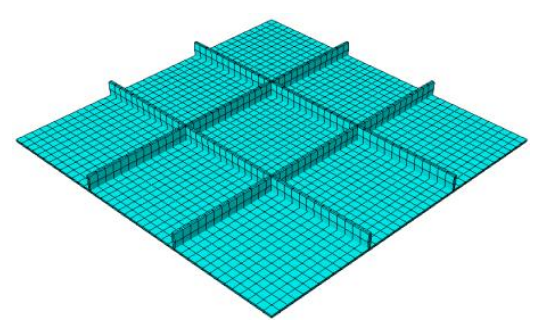

Model 6

Fig. 2. Geometrical configurations of stiffened plates

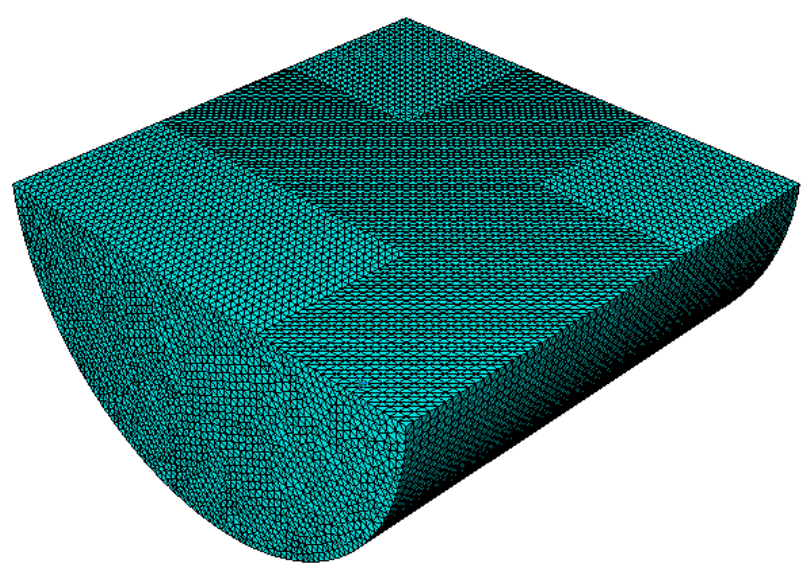

Fig. 3. Finite Element Model (Fluid region ) 
$\sigma_{d y}=\sigma_{y}\left[1+|\dot{\epsilon} / D|^{1 / q}\right]$

where $\sigma_{d y}$ is the material's dynamic yielding stress, $\sigma_{y}$ is the material's yielding stress, $\dot{\epsilon}$ is strain rate, and $D$ and $q$ are material parameters, whose values are normally $\mathrm{D}=40 \sec ^{-1}$ and $q$ $=5$ for steel.

The fluid region of the model is represented by the acoustic fluid domain. Its properties are the bulk modulus and density. In this numerical investigation, commonly accepted values for the sea water were stated in [22]. The bulk modulus is $2140.4 \mathrm{MPa}$ and the density of the seawater is $1000 \mathrm{~kg} / \mathrm{m}^{3}$.

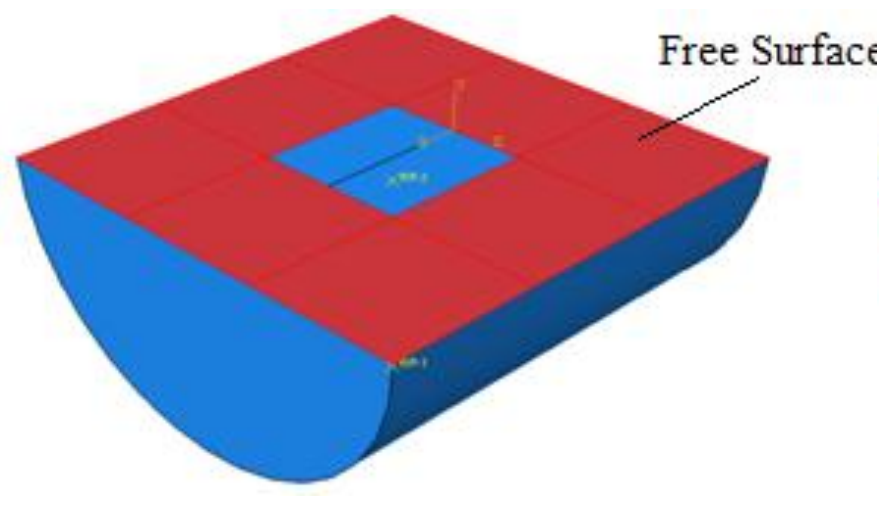

Free Surface

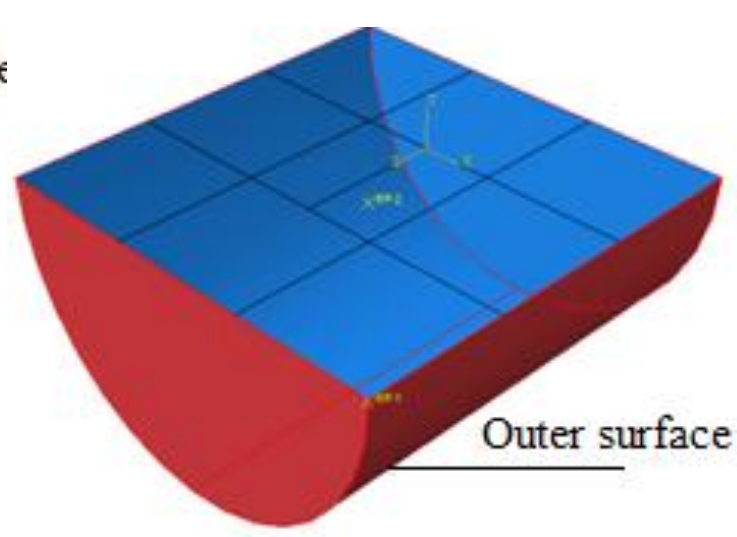

Outer surface

Fig. 4. The outer and free surface used in fluid model

Table2: Plastic material properties for the used steel [23]

\begin{tabular}{c|c}
\hline \hline True Stress (Pa) & True Plastic Strain \\
\hline \hline $300 \times 10^{6}$ & 0.000 \\
\hline $350 \times 10^{6}$ & 0.025 \\
\hline $375 \times 10^{6}$ & 0.100 \\
\hline $394 \times 10^{6}$ & 0.200 \\
\hline $400 \times 10^{6}$ & 0.350 \\
\hline \hline
\end{tabular}

\subsection{Convergence study}

A convergence study has been carried out to choose the optimum mesh for the model. The proposed finite element mesh contains one variable (n) number of divisions along the plate side, which affect the number of elements in the model. Varying the number (n) affects the accuracy of the results. The elements throughout the convergence study have an aspect ratio 1:1. The steel plate of model (1), as shown in Figure (2), has been used to perform the convergence study on it. This plate is a square steel plate with fixed sides of side length 3000 $\mathrm{mm}$ and thickness $20 \mathrm{~mm}$. Three different models consisting of grids of shell elements of size $0.0375 \mathrm{~m}, 0.075 \mathrm{~m}$ and $0.15 \mathrm{~m}$ representing fine, medium and coarse meshes respectively were used to verify the accuracy of the finite element models of the plates. The plate is loaded due to the UNDEX with charge mass $5 \mathrm{~kg}$ TNT at standoff distance of $5 \mathrm{~m}$ from the center of the plate. For each considered mesh, the maximum displacement in the middle is compared. 


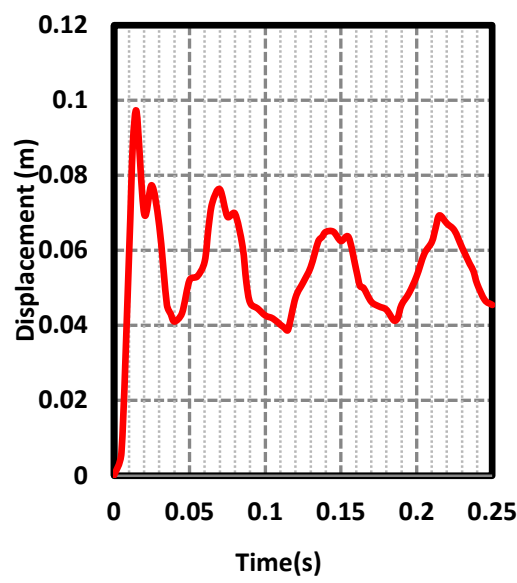

(a) with $0.15 \mathrm{~m}$ mesh size

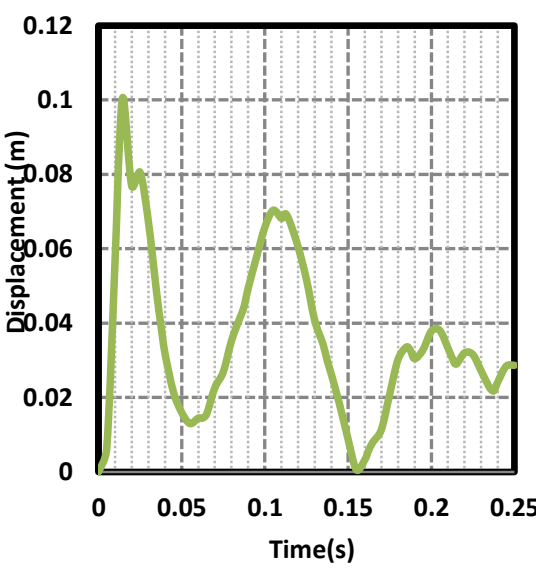

(b) with $0.0375 \mathrm{~m}$ mesh size

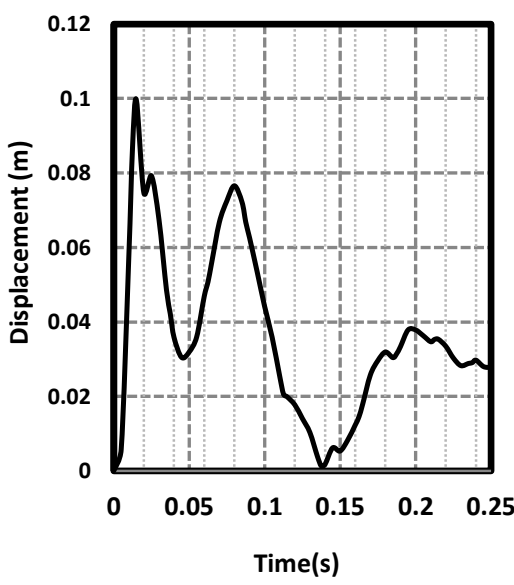

(c) with $0.075 \mathrm{~m}$ mesh size

Fig. 5. Displacement distribution at the plate center for model 1

The obtained results of the convergence study show that the maximum displacement for the model consisting of grids of shell elements size of $0.15 \mathrm{~m}$ is $9.67 \mathrm{~cm}$. For the model consisting of grids of shell elements size of $0.075 \mathrm{~m}$, the maximum displacement is $9.97 \mathrm{~cm}$. It can be noted that the difference in maximum displacement is equal to $3.1 \%$. Also the maximum displacement for model consisting of grids of shell elements size of $0.0375 \mathrm{~m}$ is $10 \mathrm{~cm}$ and the difference is $0.31 \%$. Consequently, the mesh with elements size of $0.075 \mathrm{~m}$ is chosen to perform the whole analysis and decrease the analysis timesince all displacement are less than $1 \%$ difference from the obtained results in case of elements size $0.0375 \mathrm{~m}$, and give minimum possible element size. Figure (5) shows the displacement distribution at the center of the plate of the three different models with time.

\section{Results and Discussions}

This study is based on the plate's performance improvement ratio $I_{R}$ for different effective studied parameters. The improvement ratio $I_{R}$ can be expressed as the ratio between the performances of unstiffened to stiffened plate for a specified case. The parameters play an effective influence on improving the plate's performance include the stiffeners configurations, damping effect, strain rate sensitivity and the structural integrity.

\subsection{Effect of stiffeners configurations}

The inclusion of stiffeners decreases the mid-point displacement significantly. As shown in Figure (6-a) the mid-point displacement for model 1 is $99.69 \mathrm{~mm}$, while for models 2, 3, 4,5 and 6 are $69.37 \mathrm{~mm}, 70 \mathrm{~mm}, 57.82 \mathrm{~mm}$, and $55.8 \mathrm{~mm}, 62.93 \mathrm{~mm}$, respectively. Therefore, the configurations of stiffeners have an important influence on the response of the stiffened plates. Figure (6-b) shows the Improvement Ratio $I_{R}$ for all models. It can be noted also, that the best $I_{R}$ is $44.03 \%$ for model 5 and the lowest $I_{R}$ is $29.78 \%$ for model 3 .

The maximum displacement of the center point of all plate's models is monitored with time in order to evaluate the performance of the plates under the effect of shock loads. Figure 7 shows the maximum displacement values at different time history $0.01 \mathrm{sec} ., 0.015 \mathrm{sec} ., 0.02$ sec., and $0.025 \mathrm{sec}$., for the tested plates. Figure 8 shows the displacement-time history of the center point of all models. It can be noted that, for model 1 (un-stiffened plate), the maximum displacement is $57.22 \mathrm{~mm}$ at time $0.01 \mathrm{sec}$., increased to $99.69 \mathrm{~mm}$ at time $0.015 \mathrm{sec}$., then decreased to $74.7 \mathrm{~mm}$ at time $0.02 \mathrm{sec}$., and then increase to $79.26 \mathrm{~mm}$ at $0.025 \mathrm{sec}$. This results in, that the inclusion of stiffeners to the plates leads to better response of the plates to the shock wave effects. 
For model 2, plate with a central stiffener, it is found that the maximum displacement is 55.26 $\mathrm{mm}$ at time $0.01 \mathrm{sec}$, increased to $70.37 \mathrm{~mm}$ at time $0.015 \mathrm{sec}$, and then decreased to $62.3 \mathrm{~mm}$ and $54.79 \mathrm{~mm}$ at times $0.02 \mathrm{sec}$ and $0.025 \mathrm{sec}$ respectively.

For model 3, plate with two stiffeners, it is found that the maximum displacement at time $0.01 \mathrm{sec}$ is $59.5 \mathrm{~mm}$, increased to $66.76 \mathrm{~mm}$ at time $0.015 \mathrm{sec}$, then decreased to $54.78 \mathrm{~mm}$ and $32.54 \mathrm{~mm}$ at times $0.02 \mathrm{sec}$ and $0.025 \mathrm{sec}$ respectively.

For model 4, plate with three stiffeners, it is found that the maximum displacement at time $0.01 \mathrm{sec}$ is $47 \mathrm{~mm}$ which is less than model 1 by $17.8 \%$, increased to $60.5 \mathrm{~mm}$ at time $0.015 \mathrm{sec}$ which is less than model 1 by $39.3 \%$, then decreased to $43.12 \mathrm{~mm}$ and $32.4 \mathrm{~mm}$ at times $0.02 \mathrm{sec}$ and $0.025 \mathrm{sec}$ respectively. For model 5, plate with one-cross stiffeners, it is found that the maximum displacement at time $0.01 \mathrm{sec}$ is $46.55 \mathrm{~mm}$ which is less than model 1 by $18.6 \%$, increased to $55.95 \mathrm{~mm}$ at time $0.015 \mathrm{sec}$ which is less than model 1 by $44.33 \%$, then decreased to $44.86 \mathrm{~mm}$ and $42.27 \mathrm{~mm}$ at times $0.02 \mathrm{sec}$ and $0.025 \mathrm{sec}$ respectively.

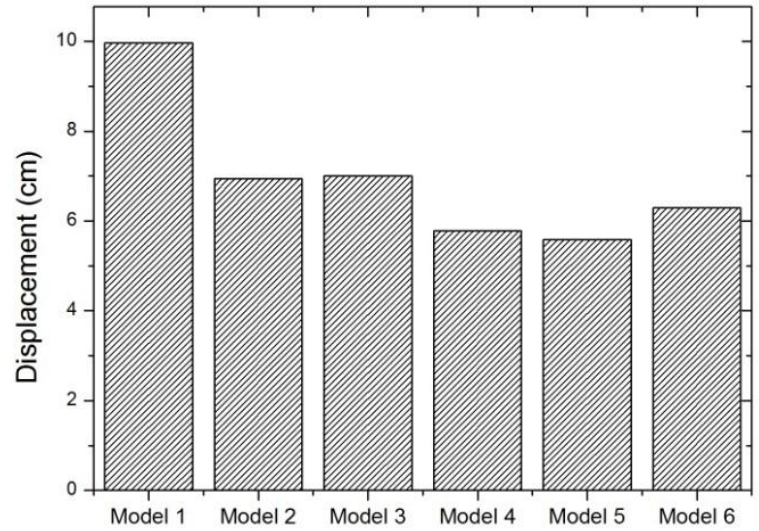

(a) Maximum displacement at the center of the plates

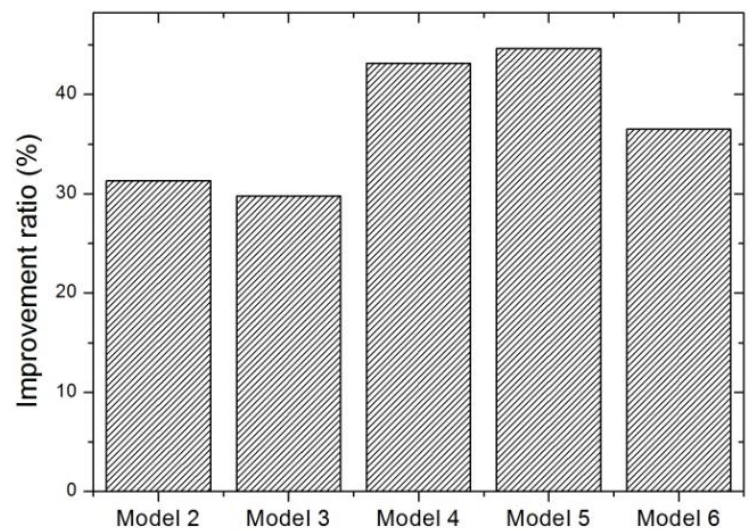

(b) Improvement ratio

Fig. 6. Maximum displacement and Improvement ratio for all models

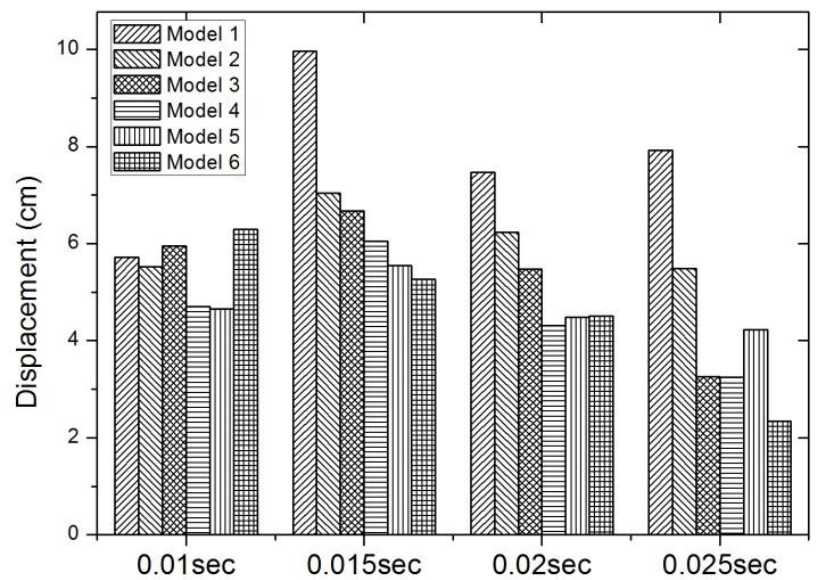

Fig. 7. Maximum displacement at the center of the plates

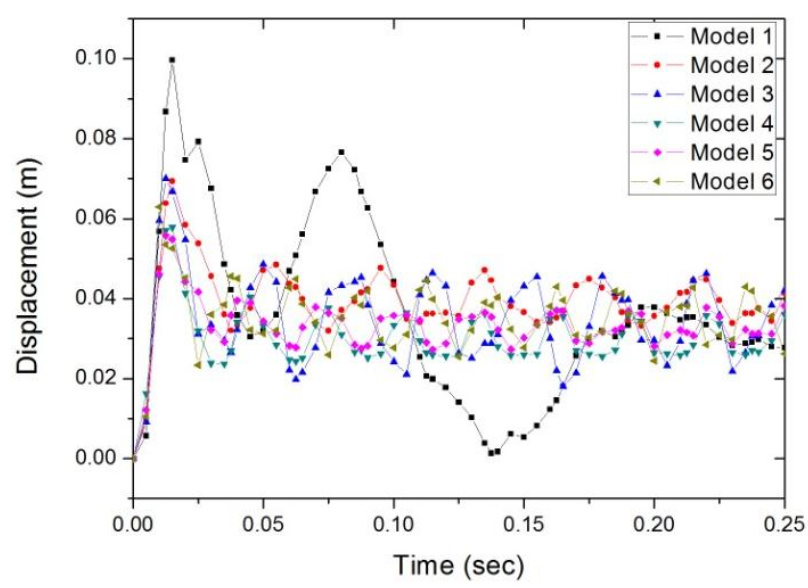

Fig. 8. Influence of stiffener configurations on the displacement at the center of the plates

For model 6, plate with two-cross stiffeners, it is found that the maximum displacement at time $0.01 \mathrm{sec}$ is $62.93 \mathrm{~mm}$, decreased to $55.95 \mathrm{~mm}$ at time $0.015 \mathrm{sec}$ which is less than model 1 by $47.23 \%$, then decreased to $45.13 \mathrm{~mm}$ and $23.4 \mathrm{~mm}$ at times $0.02 \mathrm{sec}$ and $0.025 \mathrm{sec}$ respectively. The results show that the inclusion of stiffeners to the plates increased the Improving Ratio of the plates. It can be noted that the performance of the plate model 5 is 
improved significantly with $I_{R}$ of $44.03 \%$. For better understanding the response of different plate's to the effect of shock loading, Examples of the displacement distribution contours and the von Mises stresses distribution contours with time are presented in Figures (9 and 10).
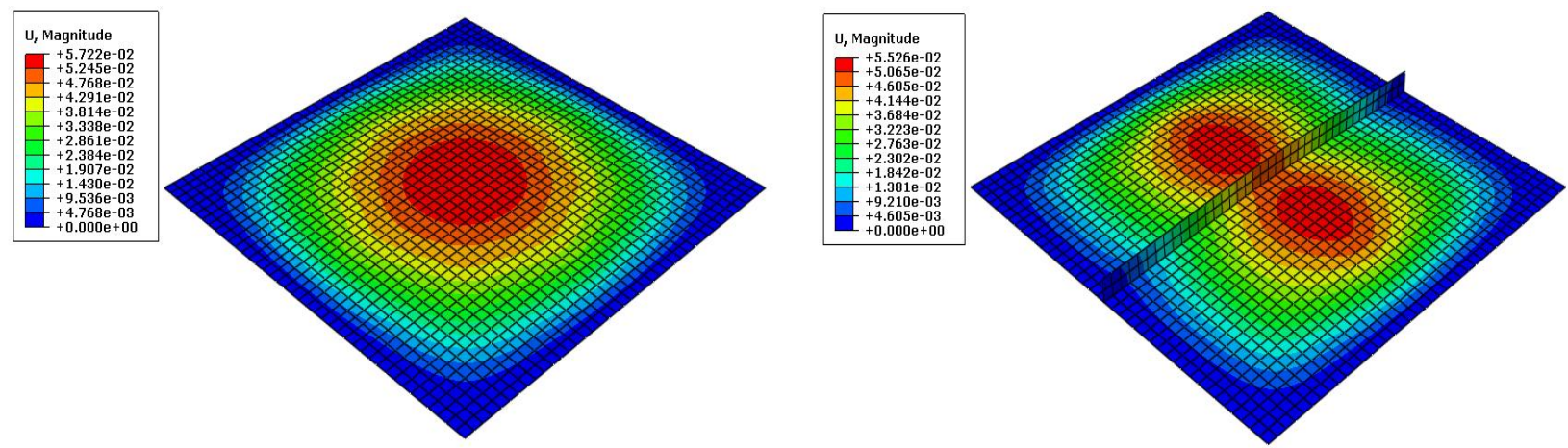

Model 1
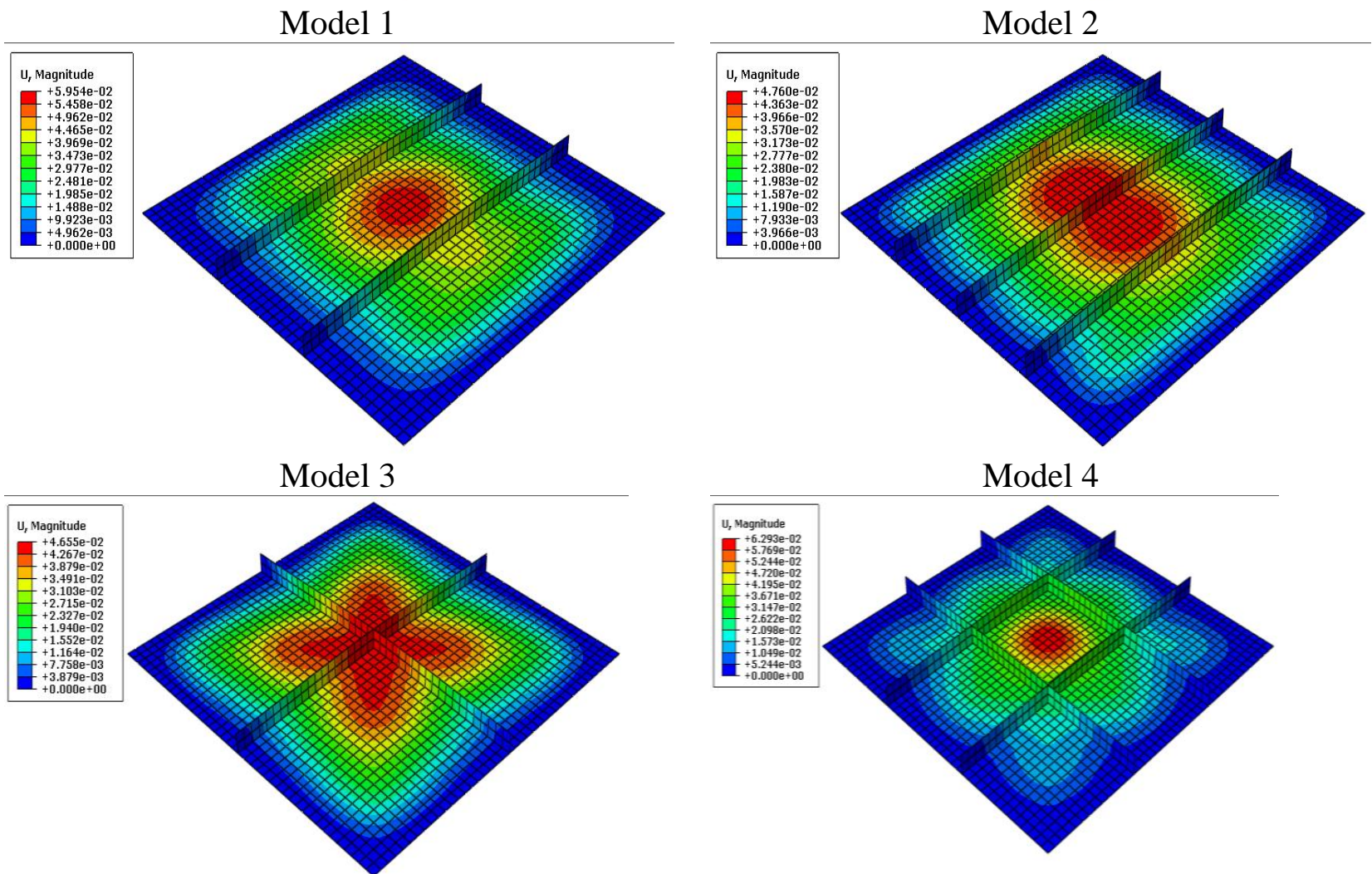

Model 5

Model 6

Fig. 9. Displacement distribution for all models at 1E-2sec

\subsection{Damping effect}

Under the effect of the applied loading, the undamped structures continue to vibrate with constant amplitude. A constant amplitude vibration is not the response that would be expected in practice since the vibrations in this type of structure would tend to die out over time and effectively disappear. The energy loss typically occurs by a variety of mechanisms, so it is needed to consider the presence of damping in the analysis to model this energy loss and introduce a more realistic structural response. To add damping to a material specify 50 as the value for the mass proportional damping factor [23]. Results of the damped analysis clearly show the effect of mass proportional damping. Figure (11) shows the displacement history of the central node for both the damped and undamped material analysis for all models. 

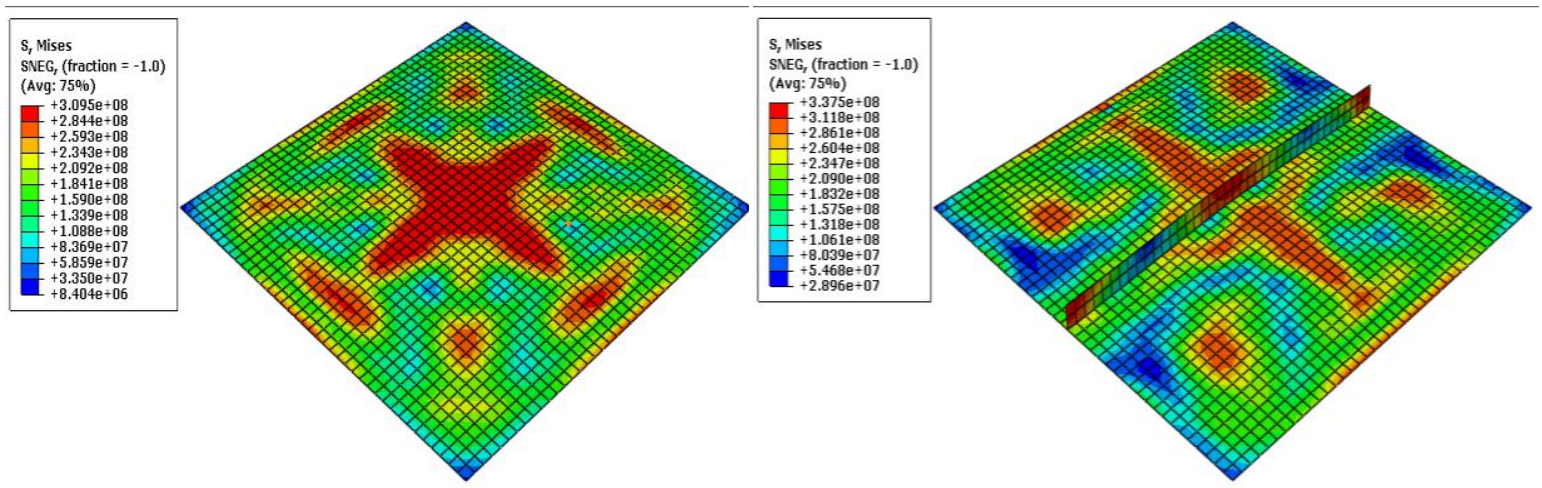

Model 1

Model 2

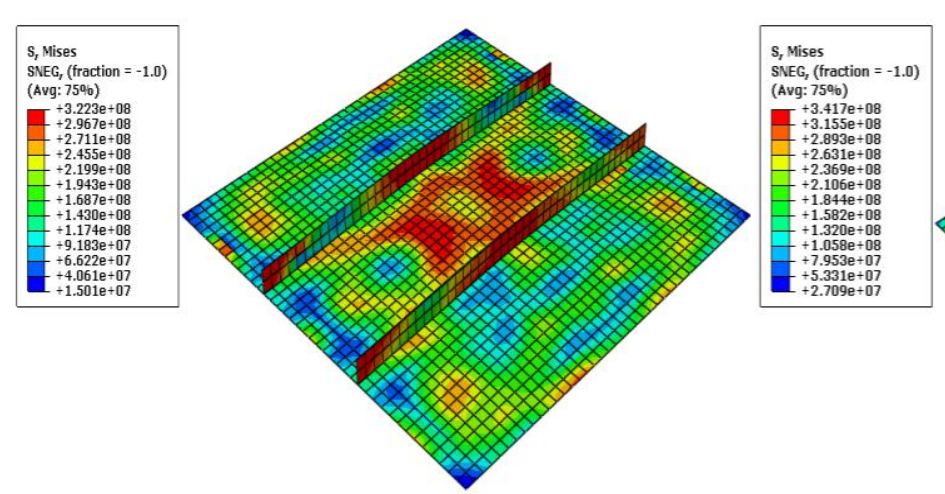

Model 3

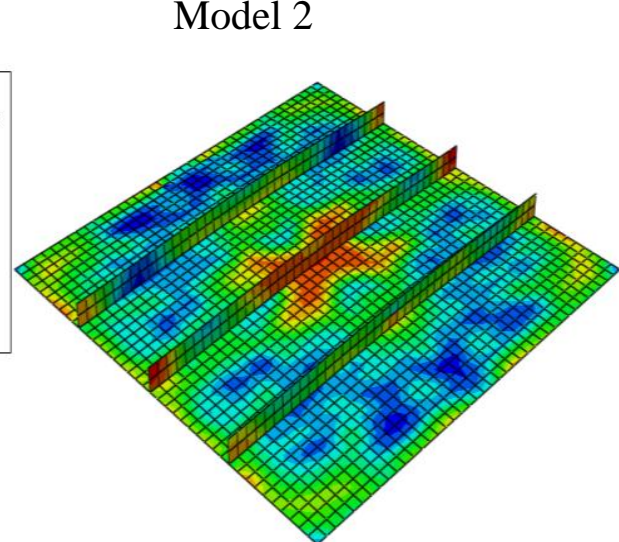

Model 4

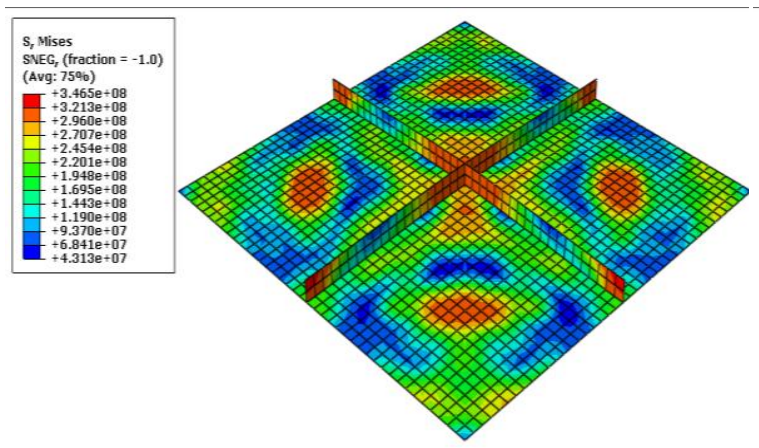

Model 5
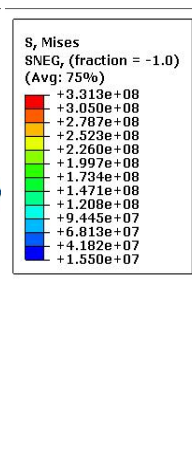

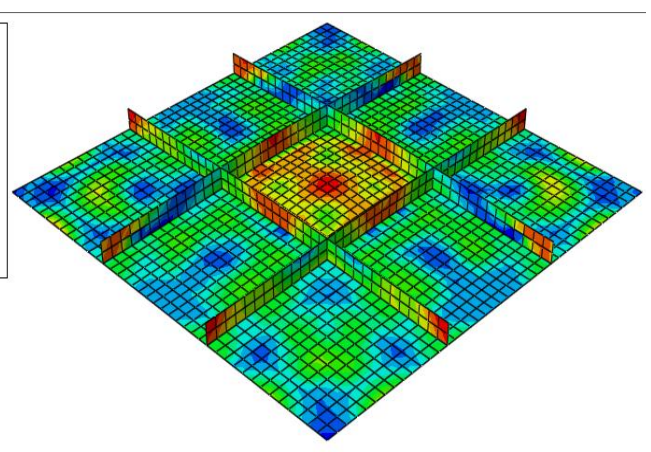

Model 6

Fig. 10.Von Mises stresses distribution for all models at 1E-2sec

Figure (12-a) shows the values of maximum central displacement in case of damped and undamped material. It can be noted that, the material with damping analysis leads to the decreasing of the maximum displacement up to $47.97 \%$ in model $5,46.35 \%$ in model 4 , $40.31 \%$ in model $6,35.45 \%$ in model 2 and $34 \%$ in model 3, respectively. These values are based on the comparison to the value obtained from model 1 without damping, which confirm that the proposal with stiffeners and special damping systems can help the structure to sustain shock loads resulting from an underwater explosion. Figure (12-b) shows the improving ratio $I_{R}$ in case of damped material analysis. It can be noted also that the performance of the tested plate of model 5 is improved significantly with $I_{R}$ of $47.97 \%$. 


\subsection{Strain rate sensitivity}

In order to investigate the strain rate sensitivity on the plate's performance under the effect of shock loading, the strain-rate effects are included in the numerical investigations in this section. The strain-rate effect is included by adjusting the material dynamic yield stress at each Gauss point according to the Cowper-Symonds strain rate mode as mentioned in Eq (9). In this study the material parameters defined as $\mathrm{D}=40 \mathrm{sec}^{-1}$ and $\mathrm{q}=5$ as recommended by Jones [21].

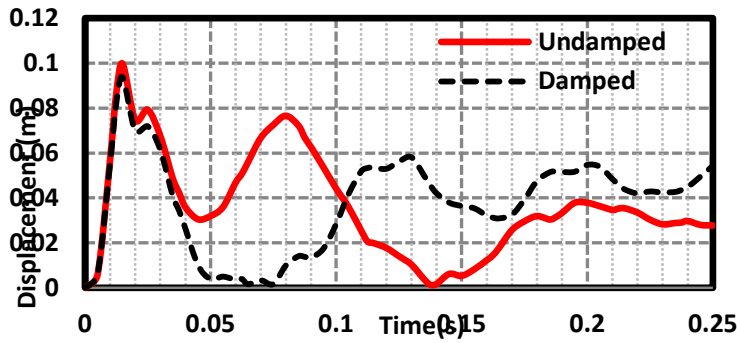

Model 1
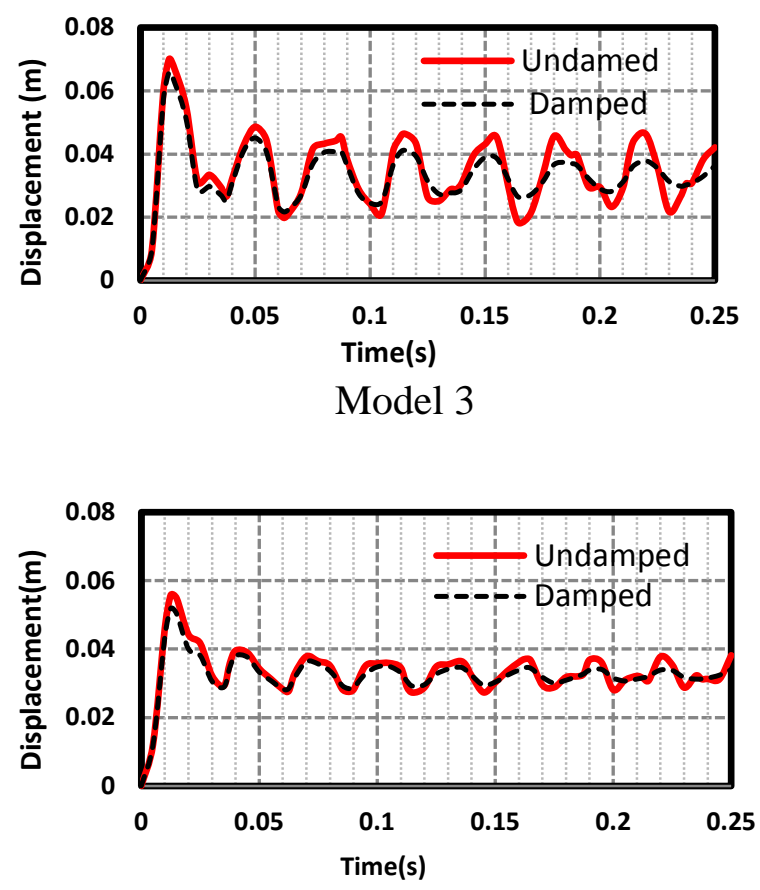

Model 5

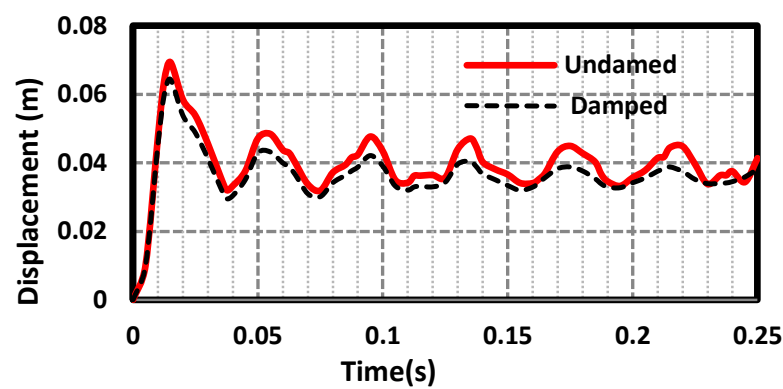

Model 2
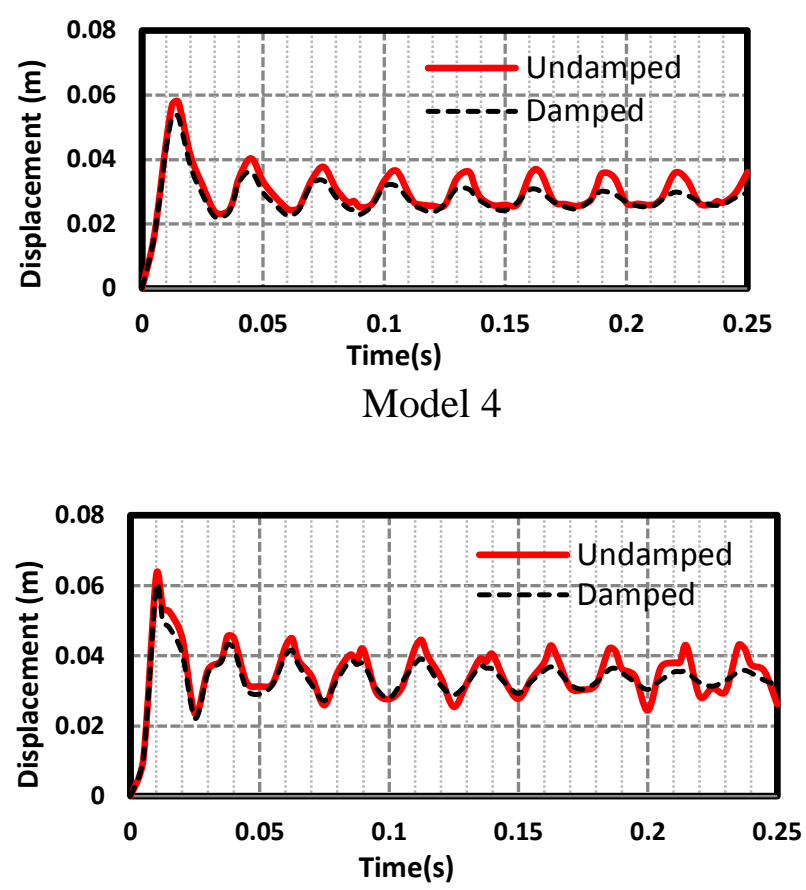

Model 6

Fig. 11. Damping effect on the displacement in the central node

Figure. 13 shows the effect of inclusion the strain rate on the performance of the different plates. The mid-point displacement for model 1 is $99.69 \mathrm{~mm}$ without strain rate inclusion and $84.88 \mathrm{~mm}$ when strain rate is included. For model 2, the mid-point displacement without strain rate and with strain rate is $69.37 \mathrm{~mm}$ and $60.8 \mathrm{~mm}$ respectively. Figure 13 shows also that the variation of center displacement with time in case of with/without rate dependent which show that, the results are very sensitive to the material data. 


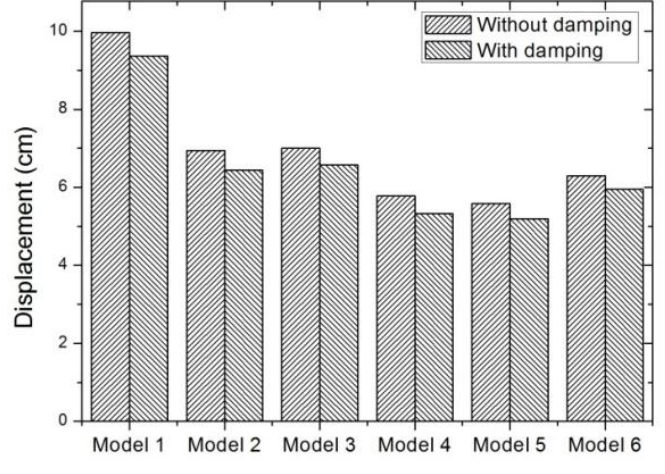

(a) Max displacement at the center of the plates

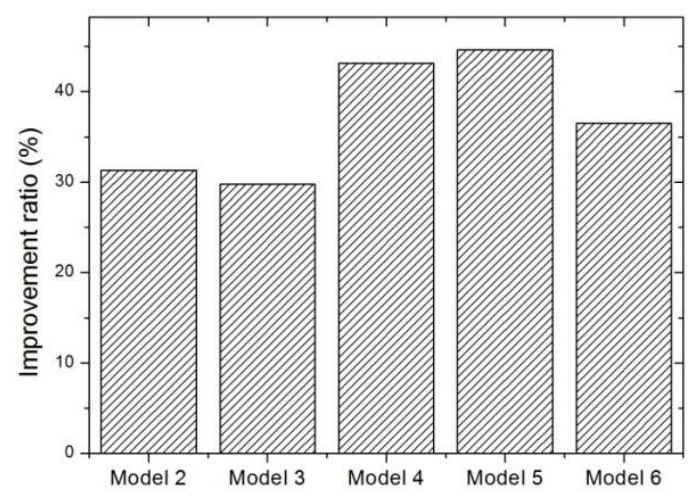

(b) Improvement ratio (With damping)

Fig. 12. Damping effect on the plates performance

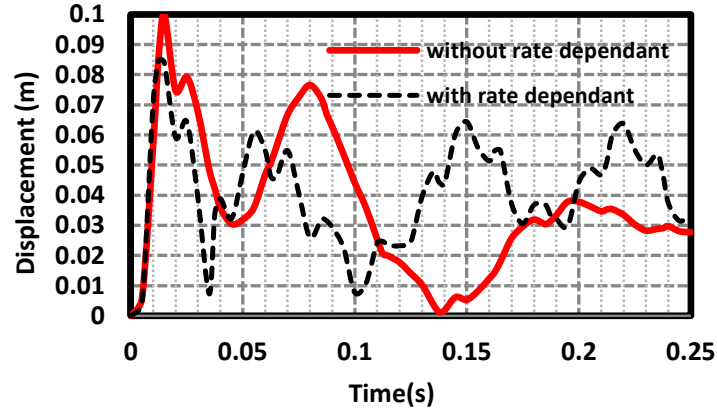

Model 1

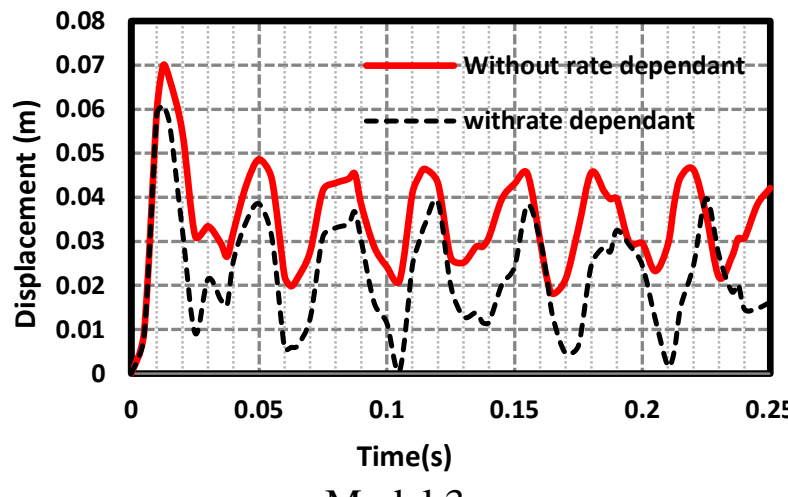

Model 3

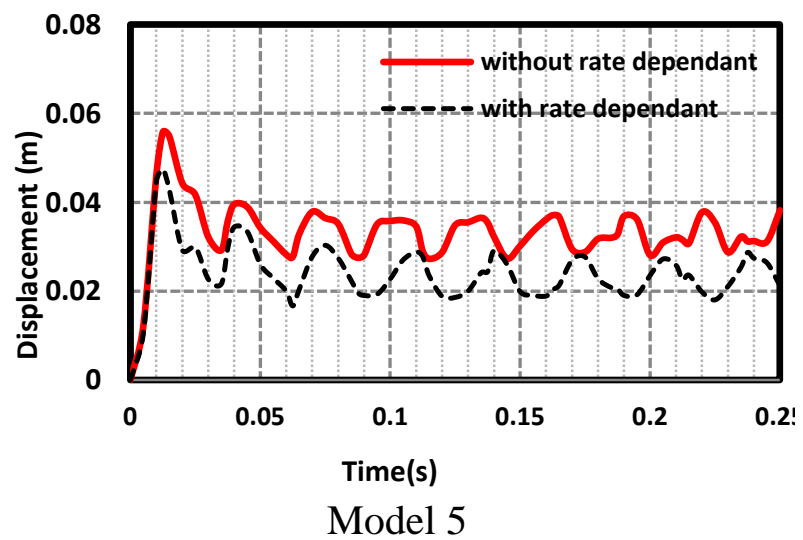

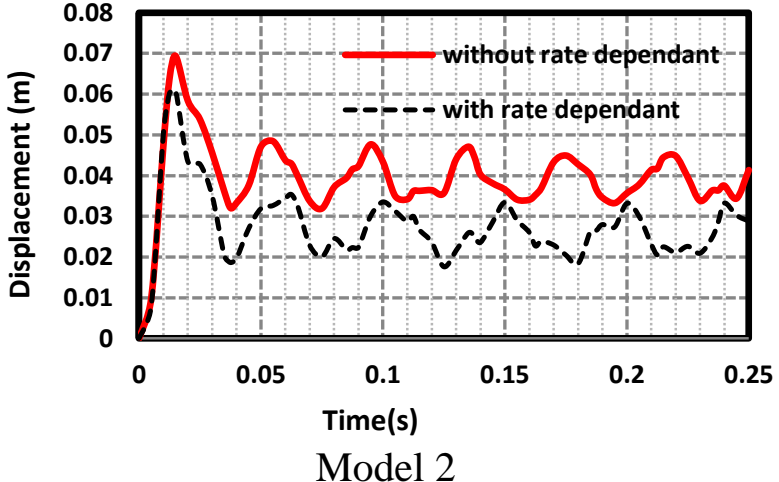
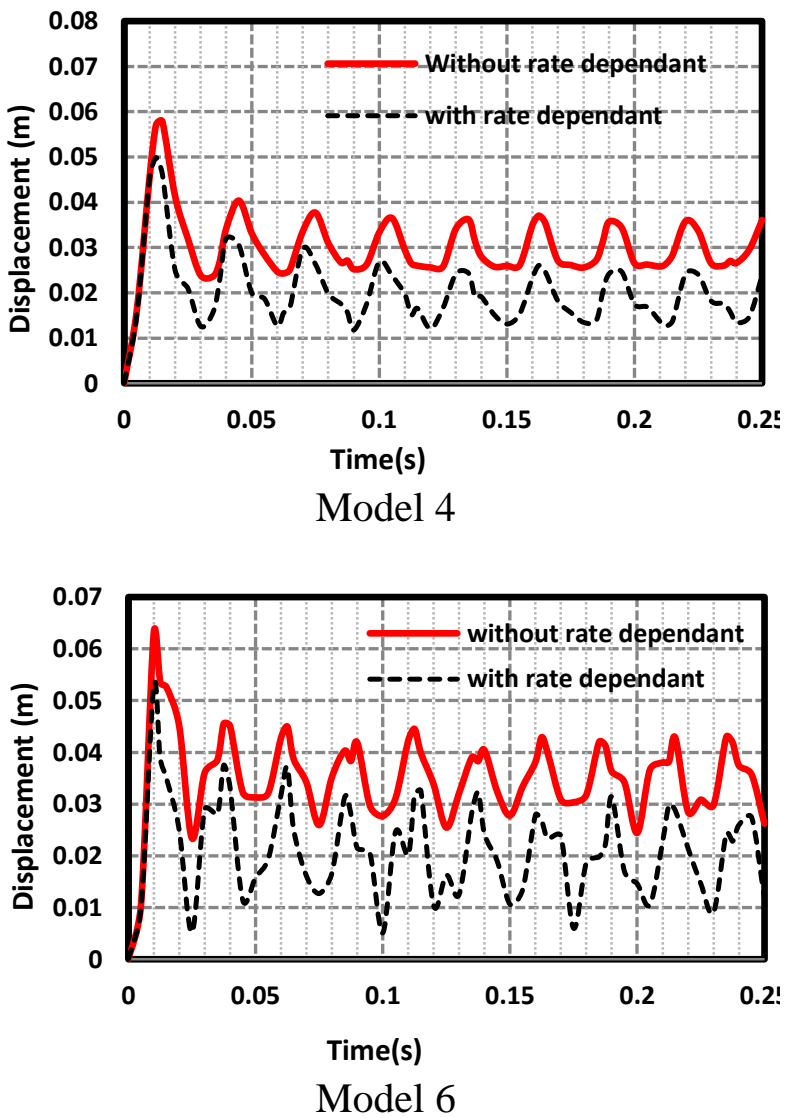

Fig. 13.Rate dependent effect on the displacement in the central node 
Figure (14) shows the maximum displacement values of the central node for both with/without rate dependent analysis and the improving ratio $\mathrm{I}_{R}$. It can be concluded that the best $I_{R}$ is $52.45 \%$ for model 5 and the lowest $I_{R}$ is $38.93 \%$ for model 3. Results show that when the strain-rate effect is taken into account, the yield stress increases as the strain rate. Thus, because the elastic modulus is higher than the plastic modulus, it is noted that the analysis with strain rate will be much stiffer, resulting in a decrease in the mid-point displacement.

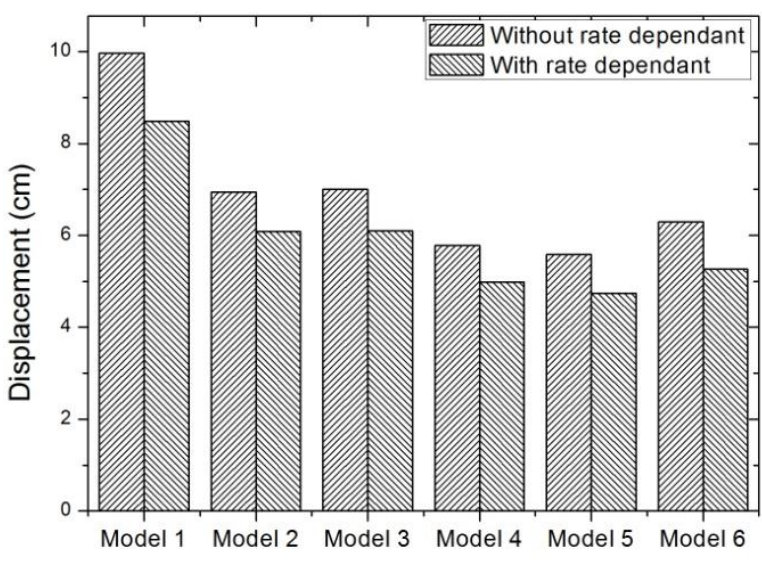

(a) Max displacement at the center of the plates

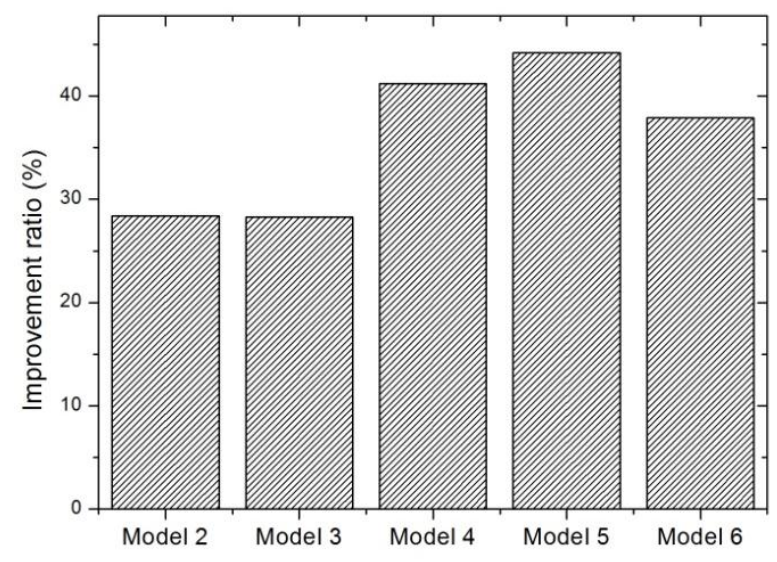

(b) Improvement ratio(With rate Dependent)

Fig. 14. Maximum displacement at the central node and the improvement ratio for both with/without rate dependent

Figure (15) shows a contour plot of von Mises stress at the end of the analysis, the regions of high stress concentration are analyzed which confirm that model 5 is the best model and its $I_{R}$ is $16.13 \%$. It is founded that $I_{R}$ for model 4 and 6 are $13.05 \%$ and $4.86 \%$, respectively, and the lowest $\mathrm{I}_{\mathrm{R}}$ is for model 3 .

\section{Conclusions}

From the non-linear dynamic finite element analyses carried out in this study to optimize the configuration of the plates to resist the underwater shock loading, the following main conclusions can be drawn:

- The displacement-time histories under shock loadings are presented which will be used in designing stiffened steel panels so as to enhance the resistance to underwater shock damage. The effect of stiffener configurations is very important, since it can affect drastically the overall behavior of the plates as indicated in this study.

- From the obtained results, the proposed model with special damping systems can help structures to sustain shock loads resulting from an underwater explosion. The inclusion of a damping material can absorb energy under shock loads and help to reduce the force transmitted to the main structure. Also, the damping material can help to reduce the displacement of the plate.

- The inclusion of strain-rate effect results in a much stiffer response, introducing lower midpoint displacement. Thus, the strain effect should be taken into account, when analyzing structures subjected to underwater shock loading. The inclusion of strain-rate effect is more effective than the case with special damping system, and finally it can reduce the displacement of the plate. 


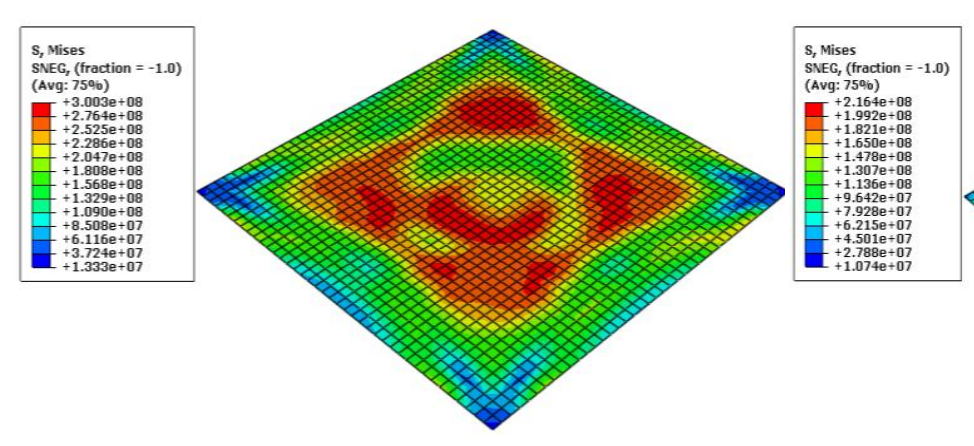

Model 1
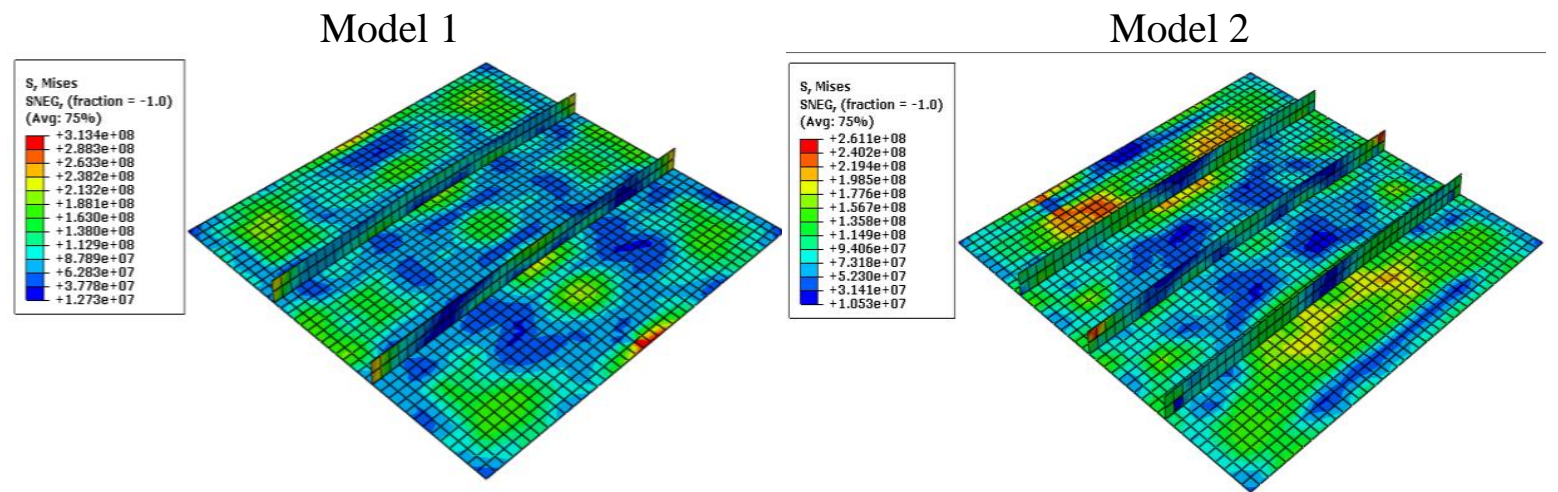

Model 3

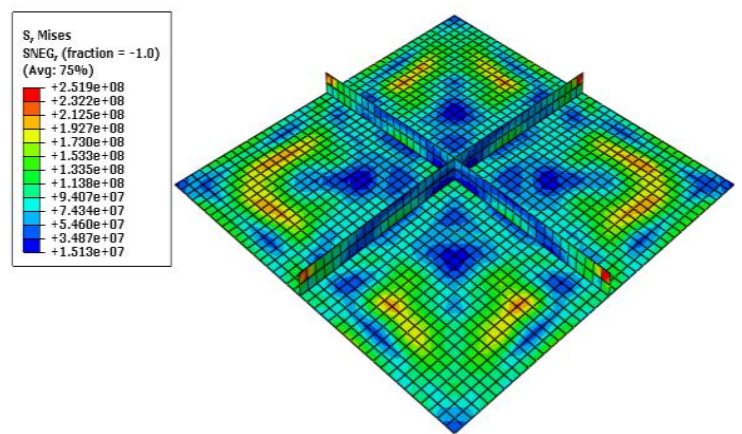

Model 5
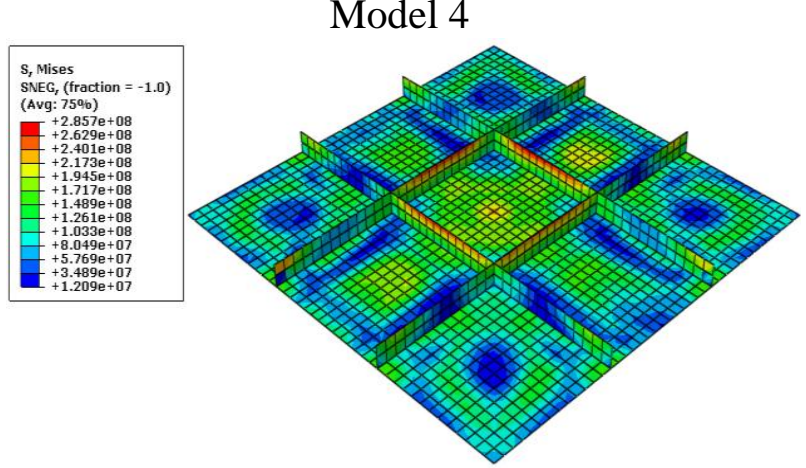

Model 6

Fig. 15. Contour plot of von Mises stress at the end of the analysis

\section{References}

[1] W. Baker, Explosions in Air, University of Texas Press, Austin, 1973.

[2] Kwon, Y.W. and Cunningham, R.E., 1998. Comparison of USA-Dyna Finite Element Models for a Stiffened Shell Subject to Underwater Shock, Computers and Structures, 66, 127-144.

[3] Kwon, Y.W. and Fox, P.K., 1993. Underwater Shock Response of a Cylinder Subjected to a Side-on Explosion, Computers and Structures, 48, 637-646.

[4] McCoy, R.W. and Sun, C.T., 1997. Fluid-Structure Interaction Analysis of a Thick Section Composite Cylinder Subjected to Underwater Blast Loading, Composite Structures, 37, 45-55.

[5] Shin, Y.S. and Hooker, D.T., 1996. Damage Response of Submerged Imperfect Cylindrical Structures to Underwater Explosion, Computers and Structures, 60, 683693.

[6] Arden, K.E., 1995. Use of MSC/NASTRAN in Predicting Structural Response to an Underwater Explosion, MSC 1995 World Users' Conference Proceedings, California, May 1995, 51. 
[7] Adamczyk, R. and Cichocki, K., 1997. Analysis of the Shock Response of an Underwater Structure Subjected to a Far-Field Explosion, Proceedings of ABAQUS Users' Conference, Milan, ITALY, June 1997, 73-87.

[8] Cichocki, K., 1994. Computer Analysis of Dynamic Response due to Underwater Explosion on Hybrid Structure, Proceedings of ABAQUS Users' Conference, Newport, June 1994, 207-220.

[9] Fatih Aruk and Ata Mugan, 2006 Finite Element Analysis of Response of a Floating Structure to an Underwater Explosion' I.T.U. Mech. Eng. Dept., Taksim 34437 Istanbul, Turkey

[10] Jacinto, A. C.; Ambrosini, R. D.; Danesi, R. F. 2001 Experimental and computational analysis of plates under air blast, International Journal of Impact Engineering 25(10): 927-947.

[11] Schubak, R. B. 1991. Nonlinear rigid-plastic modelling of blast loaded stiffened plates. $\mathrm{PhD}$ thesis, University of British Columbia, Vancouver.

[12] Schubak, R. B.; Anderson, D. L.; Olson, M. D. 1989a. Simplified dynamics analysis of rigid-plastic beams, International Journal of Impact Engineering 8(1): 27-42.

[13] Schubak, R. B; Olson, M. D.; Anderson, D. L. 1989b. Nonlinear analysis of one-way stiffened plates under blast load, in Proc. of the 1st International Conference "Structures under Shock and Impact". Ed. by P. S. Bulson. July 1989, Cambridge, MA, USA. Amsterdam: Elsevier, 345-354.

[14] A. Kadid, 2008 Stiffened Plates Subjected to Uniform Blast Loading, Jornal of Civil Engineering and Management.

[15] A. Forghani, C. McGregor, S. McClennan, R. Vaziri, F. Ellyin, A. Poursartip, A. Bouamoul, Modelling of damage development in blast loaded composite panels, in: The 16th International Conference on Composite Materials, Kyoto, 2007, pp. 1-8.

[16] Ionel Chirica, Doina Boazu, Elena-Felicia Beznea'Response of ship hull laminated plates to close proximity blast loads' Computational Materials Science 52 (2012) 197203

[17] C.Y. Jen Coupled acoustic-structural response of optimized ring-stiffened hull for scaled down submerged vehicle subject to underwater explosion/Theoretical and Applied Fracture Mechanics 52 (2009) 96-110

[18] Cole RH. Underwater explosions. New York: Dover Publications Inc.; 1948.

[19] Taylor GI. The pressure and impulse of submarine explosion waves on plates. Compend Underwater Explos Res ONR 1950;1:1155-74.

[20] R. Kalavalapally et al., Multidisciplinary optimization of a lightweight torpedo structure subjected to an underwater explosion/ Finite Elements in Analysis and Design 43 (2006) 103-111

[21] AM. Zhang et al. The interaction of an underwater explosion bubble and an elasticplastic structure. Applied Ocean Research 30 (2008) 159-171

[22] Abaqus, 2010. Version 6.10, Example Problems Manual.

[23] ABAQUS Tutorial, Getting Started with ABAQUS, interactive Edition, version 10.1, Published by Hibbitt, Karlsson And Sorensen Inc. USA, 2010.

[24] Bjorno L, Levin P. Underwater explosion research using small amount of chemical explosives. Ultrasonics 1976:263-7.

[25] C.-C. Liang, Y.-S. Tai Shock responses of a surface ship subjected to noncontact underwater explosions/ Ocean Engineering 33 (2006) 748-772

[26] Cole RH. Underwater explosions. New York: Dover Publications Inc.; 1948. 